\title{
Descrição de um gênero novo e cinco espécies novas de Neocoelidiinae (Hemiptera, Auchenorrhyncha, Cicadellidae) ${ }^{1}$
}

\author{
Ana Paula Marques-Costa² \& Rodney R. Cavichioli²
}

${ }^{1}$ Contribuição número 1670 do Departamento de Zoologia, Universidade Federal do Paraná.

${ }^{2}$ Programa de Pós-Graduação em Entomologia, Departamento de Zoologia, Universidade Federal do Paraná. Caixa Postal 19020, 81531-980 Curitiba-PR, Brasil. apcm@ufpr.br; cavich@ufpr.br

\begin{abstract}
Description of a new genus and five new species of Neocoelidiinae (Hemiptera, Auchenorrhyncha, Cicadellidae). A new genus of Neocoelidiinae, Paracoelidiana gen. nov., and five new species - Paracoelidiana hastata sp. nov., Paracoelidiana lamellata sp. nov., Paracoelidiana longipenis sp. nov., Paracoelidiana morretensis sp. nov. and Paracoelidiana recifensis sp. nov. - are described. This new genus is similar to Coelidiana Oman, 1936, presenting very similar external morphology, its separation being made based only in the morphology of male genitalia. The females of the new genus are unknown. All the species are illustrated and keyed, and their known geographical distribution is given.
\end{abstract}

KEYWORDS. Geographical distribution; identification key; morphology; Paracoelidiana; taxonomy.

RESUMO. Descrição de um gênero novo e cinco espécies novas de Neocoelidiinae (Hemiptera, Auchenorrhyncha, Cicadellidae). Um gênero novo de Neocoelidiinae, Paracoelidiana gen. nov., e cinco espécies novas - Paracoelidiana hastata sp. nov., Paracoelidiana lamellata sp. nov., Paracoelidiana longipenis sp. nov., Paracoelidiana morretensis sp. nov. e Paracoelidiana recifensis sp. nov. - são descritos. Esse gênero novo é próximo a Coelidana Oman, 1936, apresentando morfologia externa muito semelhante, sua separação sendo feita apenas com base na morfologia da genitália masculina. As fêmeas do gênero novo não são conhecidas. Todas as espécies são ilustradas, uma chave para identificação das mesmas e sua distribuição geográfica conhecida são fornecidas.

PALAVRAS-CHAVE. Chave de identificação; distribuição geográfica; morfologia; Paracoelidiana; taxonomia.

Neocoelidiinae compreende uma única tribo, Neocoelidiini, atualmente com 162 espécies em 28 gêneros. No Brasil, foram registradas 55 espécies em 16 gêneros (Marques-Costa \& Cavichioli 2007 a, b). A subfamília é principalmente neotropical, havendo apenas quatro gêneros com registro para a Região Neártica: Coelella DeLong, 1953, Neocoelidia Gillette \& Baker, 1895, Cocoelidia DeLong, 1953 e Neocoelidiana DeLong, 1953 (Nielson \& Knight 2000).

A subfamília inclui cigarrinhas de tamanho pequeno a médio $(5,0-12,0 \mathrm{~mm})$, de coloração geral normalmente em tons pálidos, que podem ser identificadas pelo seguinte conjunto de características: cabeça projetada anteriormente, freqüentemente com carena marginal; coroa elevada e achatada entre os olhos; ocelos na margem anterior da cabeça ou próximos a esta; suturas frontogenais estendendo-se ou não até os ocelos; antenas extremamente longas, com escapo e pedicelo bem desenvolvidos; clípeo com ou sem intumescimento mediano ou tubérculo; mesotórax freqüentemente bem desenvolvido, a pleura estendendo-se até a região do esterno, dando aos neocelidiíneos um aspecto intumescido ventralmente; venação da asa anterior geralmente indistinta, exceto apicalmente; $\mathrm{R}_{4+5}$ e $\mathrm{M}_{1+2}$ da asa posterior geralmente confluentes pré-apicalmente.

Dietrich (2003) redescreveu a subfamília, redefinindo-a para englobar três gêneros antes pertencentes a Nirvaninae Krocodona Kramer, 1964 (com nova sinonímia, Krocobella
Kramer, 1964), Krocozzota Kramer, 1964, e Krocarites Dietrich \& Vega, 1995 - e mais dois gêneros novos - Retrolidia e Krocolidia. Afirmou que apesar destes gêneros possuírem cabeça fortemente projetada anteriormente e lobos supraantenais reduzidos, diferindo do conceito de Neocoelidiinae sensu Kramer (1964), foram incluídos em Neocoelidiinae por exibirem algumas características comuns aos neocelidiíneos, prováveis sinapomorfias para a subfamília, tais como: valva subgenital (esternito VIII) do macho fusionada às placas subgenitais, mas articulada ao pigóforo; pigóforo com dente ou espinho posteroventral e asa posterior com as veias $R_{4+5} \mathrm{e}$ $\mathrm{M}_{1+2}$ confluentes.

Entretanto, não há estudos sobre as relações filogenéticas entre os gêneros e espécies de Neocoelidiinae. Vários caracteres citados por Dietrich (2004) são muito variáveis entre os gêneros da subfamília, e provavelmente não constituem sinapomorfias para o grupo. Faz-se necessário um estudo mais aprofundado, para uma melhor caracterização dos gêneros e para testar a monofilia da subfamília.

Este trabalho inclui a descrição de um gênero novo de Neocoelidiinae, Paracoelidiana gen. nov., e de cinco espécies novas, $P$. hastata $\mathbf{s p . ~ n o v . , ~ P . ~ l a m e l l a t a ~ s p . ~ n o v . , ~ P . ~ l o n g i p e n i s ~}$ sp. nov., $P$. morretensis sp. nov. e $P$. recifensis sp. nov. É fornecida a distribuição geográfica conhecida de todas as espécies e uma chave de identificação para a separação das mesmas. 


\section{MATERIALE MÉTODOS}

As abreviaturas citadas no texto correspondem às seguintes instituições, responsáveis pelo empréstimo do material: Coleção de Invertebrados do Instituto Nacional de Pesquisas da Amazônia (INPA), Manaus, Amazonas, Brasil e Coleção de Entomologia Pe. Jesus Santiago Moure do Departamento de Zoologia da Universidade Federal do Paraná (DZUP), Curitiba, Paraná, Brasil.

Para a análise das estruturas da genitália, o abdome foi removido e aquecido em banho-maria, em solução aquosa de hidróxido de potássio $(\mathrm{KOH}) 10 \%$, seguindo as técnicas do trabalho de Oman (1949), com pequenas modificações no tempo de aquecimento (de quatro a cinco minutos, em média). Em seguida, foi lavado em água quente por aproximadamente cinco a dez minutos. As genitálias foram analisadas e desenhadas em lâminas escavadas, contendo K-Y gel Johnson \& Johnson ${ }^{\circledR}$, para manter as peças na posição desejada, para a confecção das ilustrações. Após ilustradas, as estruturas foram lavadas novamente em água quente, para retirar o excesso de $\mathrm{K}-\mathrm{Y}$ gel. Posteriormente, foram acondicionadas em microtubos, com glicerina, afixados no alfinete dos respectivos espécimes. A asa anterior foi ilustrada diretamente a partir do espécimetipo ou parátipo. As ilustrações foram feitas com o auxílio de microscópio estereoscópico Leica MZ 12.5 e microscópio óptico Zeiss Standard 20, ambos com câmara clara acoplada. Os holótipos foram fotografados utilizando-se câmera fotográfica digital Sony modelo Cyber-Shot DSC-S75 diretamente acoplada em microscópio estereoscópico Zeiss Stemi 2000-C pertencente ao Laboratório de Sistemática e Bioecologia de Coleoptera da Universidade Federal do Paraná.

A terminologia adotada segue principalmente os trabalhos de Kramer (1964) e Young $(1968,1977,1986)$, exceto para as estruturas da cabeça, cuja terminologia segue o trabalho de Hamilton (1981), conforme sugerido por Mejdalani (1998); a venação das asas segue Comstock \& Needham $(1898,1899)$, como sugerido por Triplehorn \& Johnson (2005) e Oman (1949); a posição das cerdas da tíbia posterior segue Rakitov (1998). As medidas são fornecidas em milímetros. As informações entre colchetes são informações adicionais, acrescentadas pelos autores, não explícitas nas etiquetas dos espécimes.

\section{Paracoelidiana gen. nov.}

Figs. 1-61

Espécie-tipo: Paracoelidiana lamellata sp. nov.

Diagnose. Sutura coronal indistinta; carena presente entre coroa e fronte; margem posterior do pronoto emarginada (Figs. 1, 11, 24, 35 e 46); venação da asa anterior indistinta, exceto sutura claval, células apicais e porção pré-apical (Figs. 3, 14, 26,38 e 49 ); asa posterior com veias $\mathrm{R}_{4+5}$ e $\mathrm{M}_{1+2}$ convergentes pré-apicalmente, fusionadas no ápice; genitália masculina: edeago com ápice da haste muito estreitado, curvado dorsalmente ou voltado posteriormente, com processo préapical de formato variável (Figs. 8, 21, 31, 44 e 54); tubo anal membranoso, em vista ventral, com lamelas ou dobras internas medianamente (Figs. 10, 23, 34 e 56).

Descrição. Em vista dorsal, corpo estreitado, não achatado dorso-ventralmente.

Cabeça. Em vista dorsal, com coroa aproximadamente pentagonal, moderadamente projetada anteriormente, tão larga quanto longa (Figs. 1, 11, 24, 35 e 46); margem anterior fortemente arqueada e angulada, com carena na transição entre coroa e fronte; margens laterais, adjacentes aos olhos compostos, elevadas e levemente carenadas (Figs. 13, 37 e 48); superfície plana, lisa, sem estrias, com máculas coronais distintas, fracamente visíveis; sutura coronal indistinta (Figs. $1,11,24,35$ e 46); ocelos na margem anterior da cabeça, na transição entre coroa e fronte, acima dos lobos supra-antenais, mais próximos aos olhos compostos que da linha mediana, não visíveis em vista dorsal; lobos supra-antenais, em vista lateral, oblíquos e levemente carenados; flagelos antenais mais longos que a metade basal das asas anteriores; fronte com comprimento cerca de 1,5 a duas vezes sua largura basal, perfil convexo, sem intumescimento central na base, não carenada; impressões musculares indistintas; suturas frontogenais atingindo os ocelos; margem apical da placa maxilar ultrapassando o ápice do clípeo; loros em formato de meialua, margens apicais não atingindo o ápice do clípeo; genas não cobrindo completamente os proepisternos, estes visíveis em vista frontal apenas pelo ápice (Figs. 2, 12, 25, 36 e 47); sutura epistomal distinta e completa, retilínea a levemente arqueada; clípeo retangular, com margens laterais paralelas e margem apical retilínea (Figs. 2, 12, 25, 36 e 47), em vista lateral, não intumescido (Figs. 13, 37 e 48).

Tórax. Pronoto pouco mais largo que a cabeça, distância trans-humeral aproximadamente igual à distância transocular; comprimento mediano um terço da distância trans-humeral; margens laterais arredondadas a anguladas, margem posterior emarginada (Figs. 1, 11, 24, 35 e 46); superfície com estrias transversais; carena dorsopleural completa, curta e evidente (Figs. 13, 37 e 48); mesotórax, em vista ventral, moderadamente intumescido; escutelo (sensu Young 1968) tão longo quanto sua largura máxima, com sulco distinto pré-apical. Asa anterior cerca de 3,5 vezes mais longa que sua largura máxima, com ápice arredondado; sem pontuações, hialina; venação indistinta, exceto pela sutura claval, células apicais e porção pré-apical; quatro células apicais, todas aproximadamente retangulares; segunda e quarta células apicais eqüidistantes da base, mais proximais que a terceira célula apical; três células anteapicais, apenas a externa fechada, as demais apenas com ápices visíveis; apêndice muito estreito restrito à primeira célula apical (Figs. 3, 14, 26, 38 e 49). Asa posterior com três células apicais, $\mathrm{R}_{4+5}$ e $\mathrm{M}_{1+2}$ convergentes pré-apicalmente, fusionando-se no ápice. Perna posterior: fórmula femoral $2+2+0$; tíbia: fileira PD densamente cerdosa, com cerdas longas e grossas, sem cerdas intercalares, uniformemente distribuídas por todo comprimento da tíbia; fileira AD com cerdas longas e grossas, espiniformes, com duas ou mais cerdas curtas intercalares; fileira $\mathrm{AV}$ com cerdas curtas e espiniformes, sem 
bases proeminentes, nos terços médio e apical da tíbia, cerdas intercalares ausentes; fileira PV densamente cerdosa, com cerdas curtas na base, crescentes em comprimento em direção ao ápice; tarsômero I tão longo quanto o comprimento da soma dos dois mais distais, com duas fileiras paralelas de microcerdas na superfície plantar.

Abdome. Genitália masculina: pigóforo de formato variável, com ou sem processos (Figs. 4, 15, 27, 39 e 50); valva subgenital fusionada às placas subgenitais; placas subgenitais fusionadas até o quarto apical ou em menor extensão, mais longas que o pigóforo (Figs. 5, 16, 17, 28, 40 e 51); estilos simples, não bifurcados, com ápice em forma de gancho esclerosado, curvado ventralmente (Figs. 6-7, 19-20, 29-30, 42-43 e 52-53); conetivo em forma de "V" (Figs. 7, 20, 30, 43 e $53)$; edeago com ápice da haste muito estreitado curvado dorsalmente ou voltado posteriormente, com processo préapical de formato variável (Figs. 8, 21, 31, 44 e 54); tubo anal membranoso, em vista ventral, com lamelas ou dobras internas medianamente (Figs. 10, 23, 34 e 56).

Comprimento total (corpo + asas anteriores): 5,0 - 7,0.

Distribuição geográfica (Fig. 62). Brasil.

Comentários. Paracoelidiana pode ser separado dos demais gêneros pelo formato característico do edeago, com ápice da haste muito estreitado e curvado dorsalmente ou voltado posteriormente, com processo pré-apical de formato variável (Figs. 8, 21, 31, 44 e 54), e pelo tubo anal que, em vista ventral, apresenta lamelas ou dobras internas medianamente (Figs. 10, 23, 34 e 56). Pela chave dicotômica de Kramer (1964), Paracoelidiana gen. nov., seria identificado como Coelidiana, e parece ser próximo a este gênero, ambos possuindo morfologia externa e coloração geral semelhantes, sua separação sendo feita apenas com base no aspecto da genitália masculina.

Etimologia. O nome do gênero é feminino e combina o prefixo para-com o nome do gênero supostamente próximo, Coelidiana.

Chave para as espécies de Paracoelidiana (machos)

1. Placas subgenitais fusionadas quase que inteiramente entre si, exceto no quarto apical (Figs. 5 e 28) ......... 2

Placas subgenitais fusionadas, porém não como acima (Figs. 16-17, 40 e 51)

2(1). Pigóforo, em vista lateral, aproximadamente retangular, com dente ventral apical (Fig. 27); placas subgenitais com ápices arredondados (Fig. 28); estilos longos e afilados (Figs. 29-30); edeago, em vista lateral, com processo pré-apical longo, curvado ventralmente e com margens serrilhadas (Figs. 31-32)

Paracoelidiana longipenis sp. nov.

Pigóforo, em vista lateral, aproximadamente triangular, com processo apical estreitado e truncado, sem dente ventral apical (Fig. 4); placas subgenitais com ápices angulados e agudos (Fig. 5); estilos longos e engrossados (Figs. 6-7); edeago, em vista lateral, com processo pré-apical curto, reto e com margens lisas (Fig. 8) ..................... Paracoelidiana hastata sp. nov.

3(1). Placas subgenitais com ápices angulados e retos (Fig. 51); edeago, em vista lateral, com processo pré-apical estreitado apicalmente, com ápice agudo e reto (Fig. 54) Paracoelidiana recifensis $\mathbf{s p . ~ n o v . ~}$

Placas subgenitais com ápices pontiagudos, curvados para fora em maior ou menor grau (Figs. 16-17 e 40); edeago, em vista lateral, com processo pré-apical não estreitado apicalmente, com ápice aproximadamente arredondado, curvado ventralmente (Figs. 21 e 44) .. 4

4(3). Pigóforo, em vista lateral, com terço apical muito estreitado e ápice curvado ventralmente em forma de gancho (Fig. 15); edeago com par de lamelas préapicais (Figs. 21-22) e, em vista lateral, processo préapical liso (Fig. 21)

Paracoelidiana lamellata $\mathbf{s p . ~ n o v . ~}$

Pigóforo, em vista lateral, com terço apical pouco estreitado e ápice arredondado com dente ventral (Fig. 39); edeago sem par de lamelas pré-apicais (Figs. 4445) e, em vista lateral, com processo pré-apical com dentículo no ápice (Fig. 44)

Paracoelidiana morretensis sp. nov.

\section{Paracoelidiana hastata $\mathbf{s p . ~ n o v . ~}$}

Figs. 1-10 e 57

Localidade-tipo: Sinop, Mato Grosso, Brasil.

Diagnose. Genitália masculina: pigóforo com processo apical estreitado e truncado (Fig. 4); placas subgenitais abruptamente estreitadas no terço apical, com ápices agudos e esclerotinização cruciforme (Fig. 5); porção pré-apical do edeago com processo estreito e pontiagudo, semelhante a uma lança (Figs. 8-9).

Medidas. Holótipo macho: comprimento total 6,87 ; comprimento mediano da coroa 0,65 ; distância transocular 1,35 ; distância interocular 0,80 ; comprimento mediano do pronoto 0,65 ; distância trans-humeral 1,60; comprimento mediano do escutelo 1,0; largura máxima do escutelo 1,0; comprimento da asa anterior 5,50; largura máxima da asa anterior 1,55; largura basal da fronte 0,60 ; comprimento da fronte 0,85 .

Descrição. Caracteres estruturais como na descrição genérica. Comprimento mediano da coroa aproximadamente igual à distância interocular e metade da distância transocular; fronte com comprimento cerca de 1,5 vezes sua largura basal; distância trans-humeral aproximadamente igual à distância transocular; asa anterior com comprimento 3,5 vezes sua largura máxima. Genitália masculina: pigóforo, em vista lateral, 


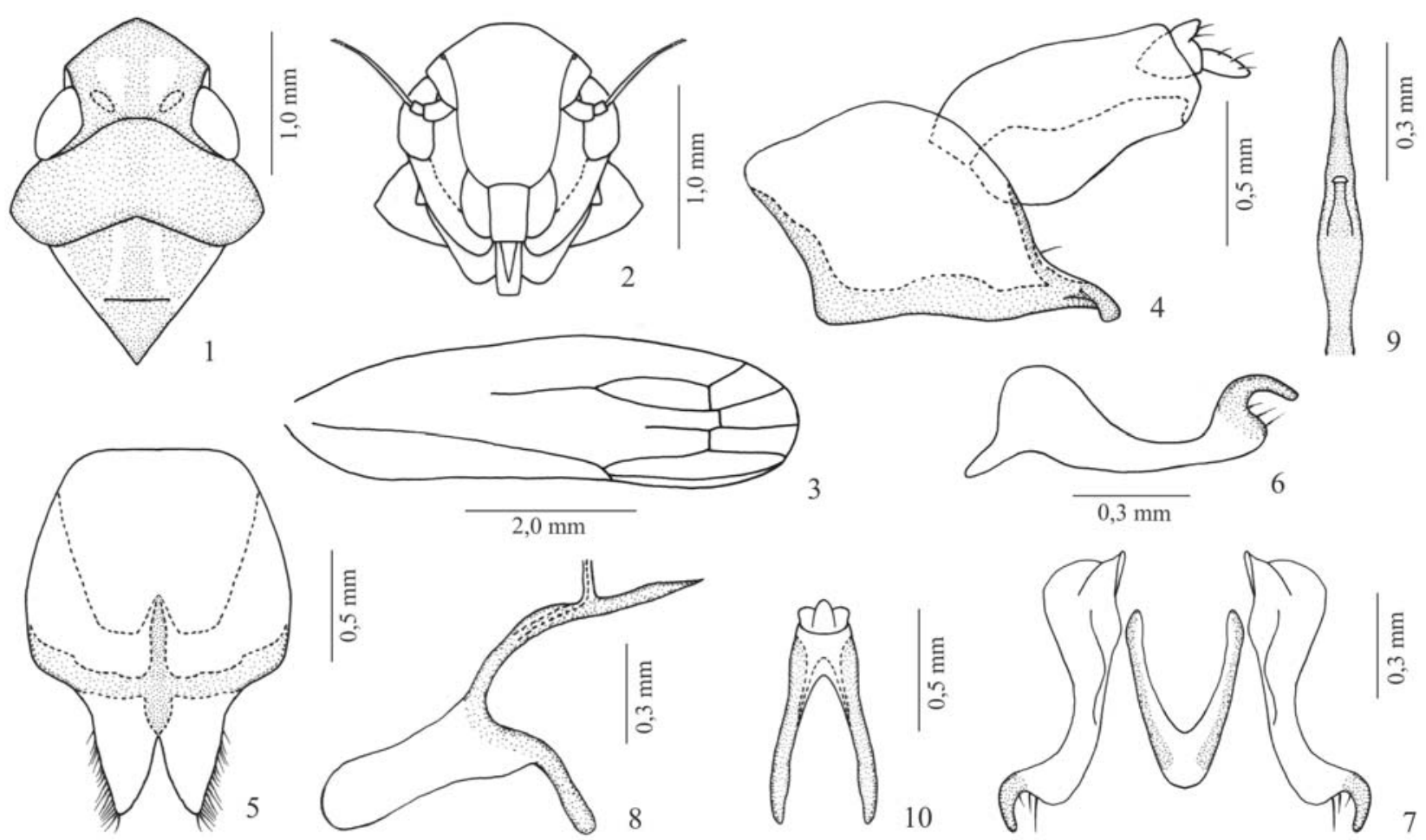

Figs. 1-10. Paracoelidiana hastata sp. nov., holótipo macho: 1, cabeça, pronoto e escutelo, vista dorsal; 2, cabeça, vista frontal; 3, asa anterior; 4, pigóforo e tubo anal, vista lateral; 5, placas subgenitais, vista ventral; 6, estilo, vista lateral; 7, estilos e conetivo, vista dorsal; 8, edeago, vista lateral; 9, ápice do edeago, vista dorsal; 10, tubo anal, vista ventral.

triangular, alargado nos terços basal e médio, estreitando-se em direção ao ápice; ápice com processo estreitado e truncado, levemente curvado ventralmente; microcerda no ápice (Fig. 4). Placas subgenitais triangulares, alargadas basalmente, estreitando-se abruptamente no terço apical; quase inteiramente fusionadas entre si, exceto no quarto apical; cada placa com comprimento cerca de três vezes sua largura máxima; ápices angulados e agudos, retos, não curvados para fora; com esclerotinização medianamente e transversalmente, em formato cruciforme; microcerdas finas e longas nas margens externas do terço apical (Fig. 5); em vista lateral, ápice retilíneo. Estilos simples, longos e engrossados, com cerdas na porção pré-apical; margens lisas (Figs. 6-7). Conetivo com porção central alargada, cerca de metade do comprimento dos estilos, articulado à base do edeago (Fig. 7). Edeago, em vista lateral, estreito e esclerosado; base com prolongamento ventral afilado e apódema dorsal membranoso, longo e arredondado; haste com terço médio curvado posteriormente e ápice curvado dorsalmente; porção pré-apical sem lamelas, com processo estreito e pontiagudo, semelhante a uma lança, reto e com margens lisas; gonóporo apical (Figs. 8-9). Tubo anal, em vista ventral, com dobras internas medianamente (Fig. 10).

Fêmea. Desconhecida.

Coloração geral. Amarela a laranja; cabeça, em vista frontal, sem manchas (Fig. 2); coroa inteiramente laranja com duas manchas centrais amarelas. Pronoto inteiramente laranja.
Escutelo com faixa longitudinal central laranja, alargada no ápice e duas manchas triangulares laranjas próximas aos ângulos laterais (Fig. 1). Asas anteriores e posteriores amarelas com veias da mesma cor. Pernas amarelas com cerdas da mesma cor.

\section{Distribuição geográfica (Fig. 62). Brasil (Mato Grosso).}

Material examinado. Holótipo macho (DZUP): BRASIL: Mato Grosso, Sinop, x.1975, M. Alvarenga leg./ DZUP \# 082920. Parátipos: idem, 3 machos (DZUP) e 2 machos (INPA); idem, [coletor anônimo e mês de coleta indeterminado], 1 macho (INPA).

Condição do holótipo. Colado ventralmente sobre triângulo; flagelos antenais, perna anterior esquerda, perna média direita, perna posterior direita e tarsômero da perna posterior esquerda quebrados; asa anterior direita quebrada na altura das células apicais; abdome dissecado.

Variações. Somente na coloração externa. Alguns parátipos apresentaram faixas longitudinais laranjas bem definidas na coroa, pronoto e escutelo, mais próxima à coloração de $P$. lamellata sp. nov. e diferente da coloração do holótipo.

Comentários. Assemelha-se a P. longipenis sp. nov. por possuir as placas subgenitais quase que inteiramente fusionadas entre si, exceto no quarto apical (Fig. 5), e pelo formato do conetivo, com a porção central alargada (Fig. 7). Entretanto, difere dessa espécie e das demais pelos outros 

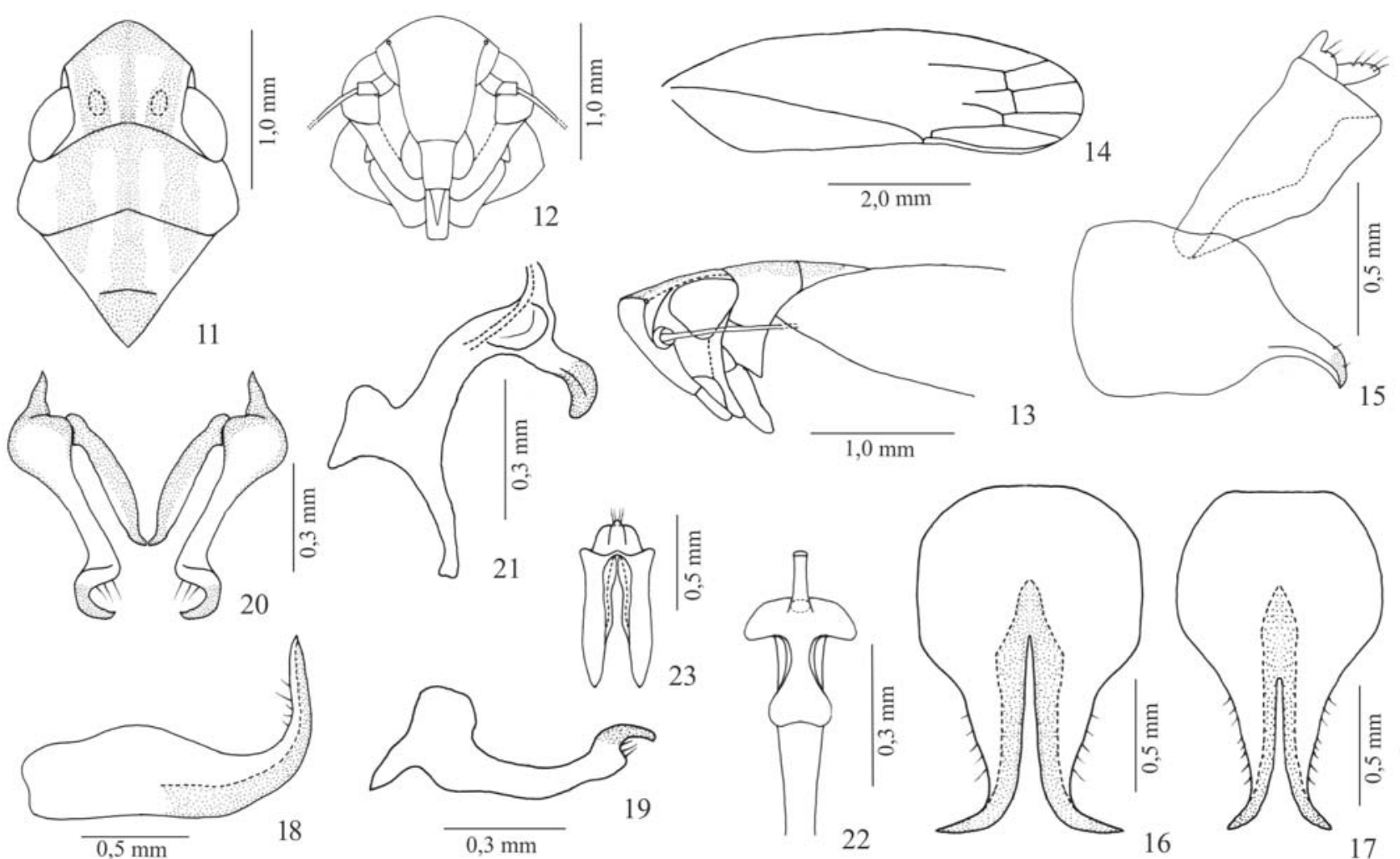

Figs. 11-23. Paracoelidiana lamellata sp. nov.: 11-16 e 18-23, holótipo macho; 17, parátipo macho: 11, cabeça, pronoto e escutelo, vista dorsal; 12, cabeça, vista frontal; 13, cabeça, pronoto e escutelo, vista lateral; 14, asa anterior; 15, pigóforo e tubo anal, vista lateral; 16-17, placas subgenitais, vista ventral; 18, placas subgenitais, vista lateral; 19, estilo, vista lateral; 20, estilos e conetivo, vista dorsal; 21, edeago, vista lateral; 22, ápice do edeago, vista dorsal; 23, tubo anal, vista ventral.

caracteres da genitália masculina. É a única espécie que possui o ápice do pigóforo com processo estreitado e truncado (Fig. 4) e edeago com processo pré-apical reto, estreito, pontiagudo e com margens lisas (Figs. 8-9).

Etimologia. Do latim, hastata = armada com lança, referindose ao processo pré-apical do edeago, estreito e pontiagudo, cujo formato assemelha-se ao de uma lança.

\section{Paracoelidiana lamellata $\mathbf{s p . ~ n o v . ~}$}

Figs. 11-23 e 58

Localidade-tipo: Sinop, Mato Grosso, Brasil.

Diagnose. Genitália masculina: ápice do pigóforo fortemente estreitado e curvado ventralmente em forma de gancho (Fig. 15); placas subgenitais fortemente esclerosadas medianamente e nos ápices, ápices afilados e pontiagudos curvados para fora (Figs. 16-18); porção pré-apical do edeago com par de lamelas e processo arredondado curvado ventralmente, ápice do processo liso e esclerosado (Figs. 2122).

Medidas. Holótipo macho: comprimento total 6,87; comprimento mediano da coroa 0,75 ; distância transocular 1,35 ; distância interocular 0,75 ; comprimento mediano do pronoto 0,60; distância trans-humeral 1,60; comprimento mediano do escutelo 0,90; largura máxima do escutelo 0,90; comprimento da asa anterior 5,25; largura máxima da asa anterior 1,50; largura basal da fronte 0,60; comprimento da fronte 1,0.

Descrição. Caracteres estruturais como na descrição genérica. Comprimento mediano da coroa igual à distância interocular e aproximadamente metade da distância transocular; fronte com comprimento cerca de duas vezes sua largura basal; distância trans-humeral aproximadamente igual à distância transocular; asa anterior com comprimento 3,5 vezes sua largura máxima. Genitália masculina: pigóforo, em vista lateral, triangular, terços basal e médio alargados e terço apical muito estreitado com ápice curvado ventralmente em forma de gancho; microcerdas no ápice (Fig. 15). Placas subgenitais triangulares, alargadas basalmente estreitando-se fortemente em direção ao ápice; fusionadas entre si na metade basal; ápices longos, afilados e pontiagudos curvados para fora; fortemente esclerosadas medianamente e nos ápices; cada placa com comprimento cerca de três vezes sua largura máxima; microcerdas nas margens externas da metade apical (Fig. 16); em vista lateral, ápice fortemente curvado para cima (Fig. 18). Estilos simples, longos e engrossados, com cerdas na porção pré-apical e margens lisas (Figs. 19-20). Conetivo cerca de 


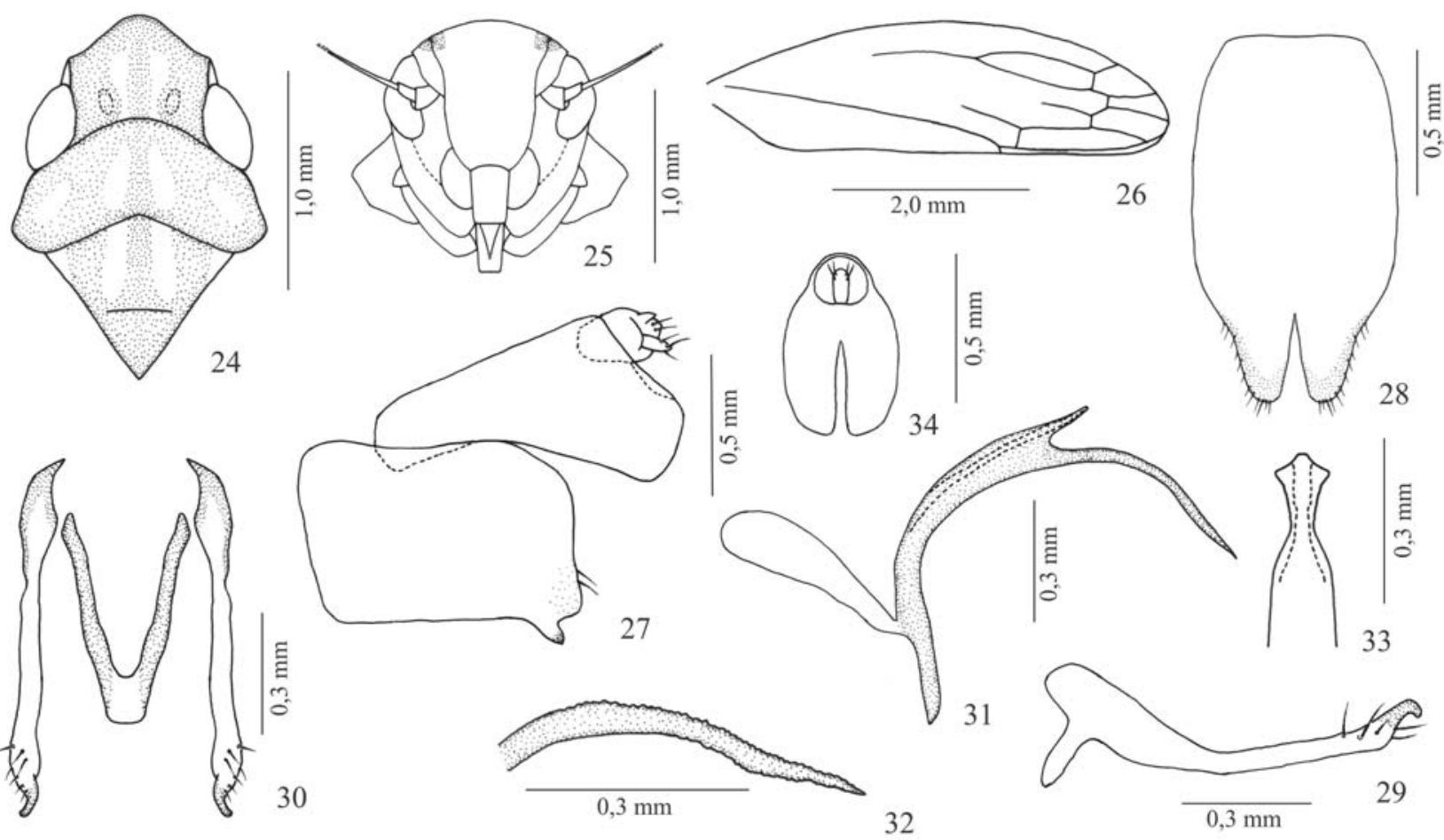

Figs. 24-34. Paracoelidiana longipenis sp. nov., holótipo macho: 24, cabeça, pronoto e escutelo, vista dorsal; 25, cabeça, vista frontal; 26, asa anterior; 27, pigóforo e tubo anal, vista lateral; 28, placas subgenitais, vista ventral; 29, estilo, vista lateral; 30, estilos e conetivo, vista dorsal; 31, edeago, vista lateral; 32, detalhe do processo do edeago, vista lateral; 33, ápice do edeago, vista dorsal; 34, tubo anal, vista ventral.

metade do comprimento dos estilos, articulado à base do edeago (Fig. 20). Edeago, em vista lateral, mais alargado e mebranoso nos terços basal e médio, fortemente estreitado no terço apical; base com prolongamento ventral afilado e apódema dorsal curto, aproximadamente quadrangular; haste com terço médio curvado posteriormente; ápice curvado dorsalmente; porção pré-apical com par de lamelas e processo arredondado curvado ventralmente, com ápice esclerosado e liso, sem dentículo (Fig. 21); em vista dorsal, processo préapical com aspecto bilobado (Fig. 22); gonóporo apical. Tubo anal, em vista ventral, com dobras internas medianamente (Fig. 23).

\section{Fêmea. Desconhecida.}

Coloração geral. Amarelo-clara com manchas laranjas; cabeça, em vista frontal, sem manchas (Fig. 12). Coroa com três faixas longitudinais e uma transversal, laranjas, sendo as longitudinais, uma central e duas laterais, e, a transversal larga na margem anterior, ligada às longitudinais. Pronoto com três faixas longitudinais laranja-claro, uma central mais larga, e duas laterais. Escutelo com faixa longitudinal central laranja e ângulos laterais da mesma cor (Fig. 11). Asas anteriores amarelas com veias da mesma cor, margem anal laranja-clara ao longo do clavo. Asas posteriores amarelas a esbranquiçadas com veias amarelas. Pernas amarelas com cerdas da mesma cor.

Distribuição geográfica (Fig. 62). Brasil (Mato Grosso).
Material examinado. Holótipo macho (DZUP): BRASIL: Mato Grosso, Sinop, x.1975, M. Alvarenga leg./ DZUP \# 082921. Parátipos: idem, 1 macho (DZUP).

Condição do holótipo. Flagelos antenais quebrados, o direito na base e o esquerdo no terço médio; pernas anteriores e médias e porção ventral do tórax colados em triângulo com cola branca; pernas posteriores quebradas; asas anteriores cobertas por escamas de Lepidoptera; ápice da asa anterior esquerda quebrado; abdome dissecado.

Variações. O parátipo apresentou as placas subgenitais fusionadas até o terço apical, com ápices mais curtos que no holótipo, mas igualmente esclerosados e curvados para fora (Fig. 17).

Comentários. Assemelha-se a P. morretensis sp. nov. pelo formato das placas subgenitais e edeago (Figs. 16-17, 21). Difere desta espécie por possuir a porção pré-apical do edeago com um par de lamelas e processo arredondado curvado ventralmente, que em vista dorsal tem aspecto bilobado (Figs. 21-22). Além disso, difere das demais espécies, por possuir pigóforo com ápice curvado ventralmente em forma de gancho (Fig. 15).

Etimologia. Do latim, lamella = lamela, placa, $a t=$ sufixo de posse; portanto lamellata, com lamelas, presentes no edeago. 

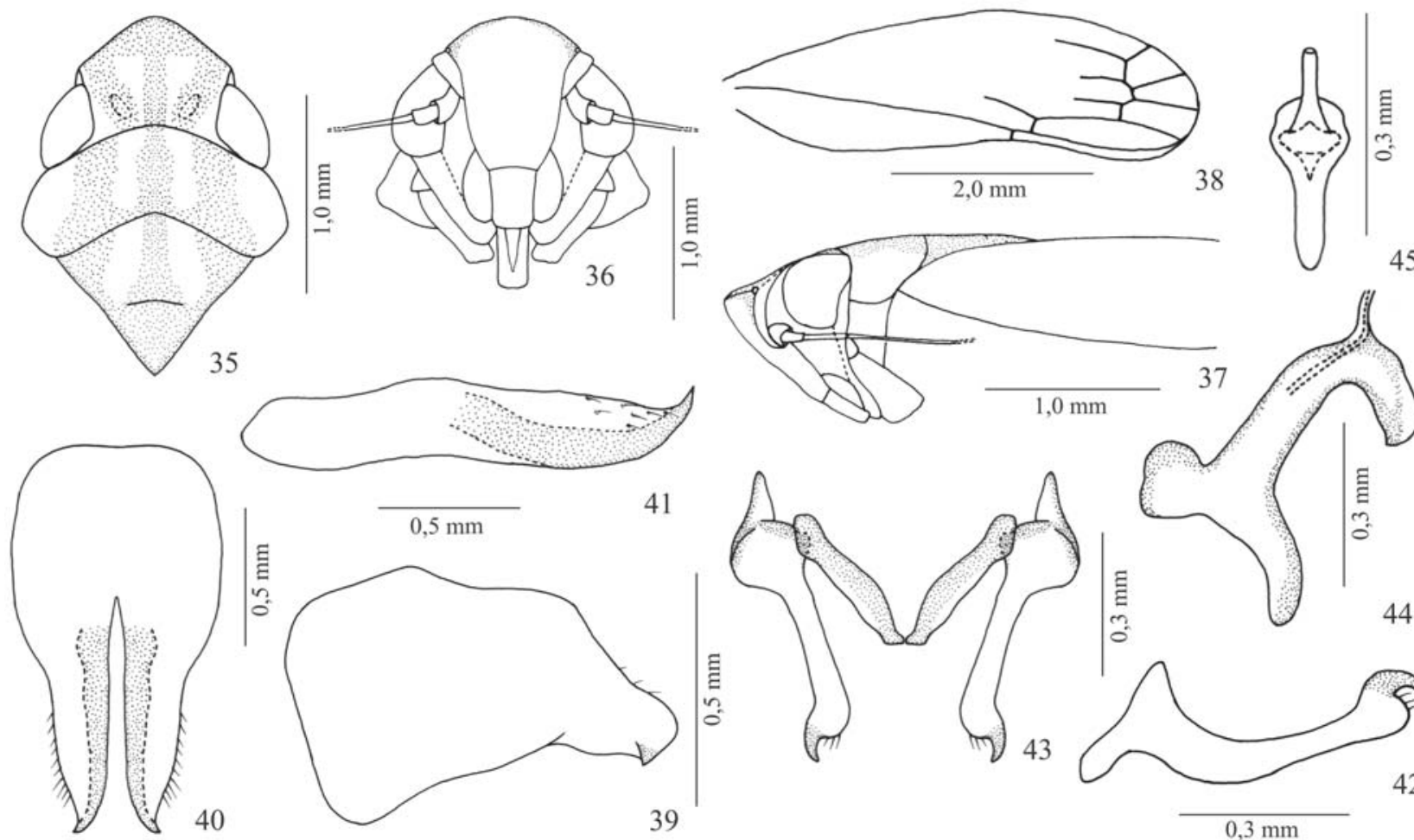

45
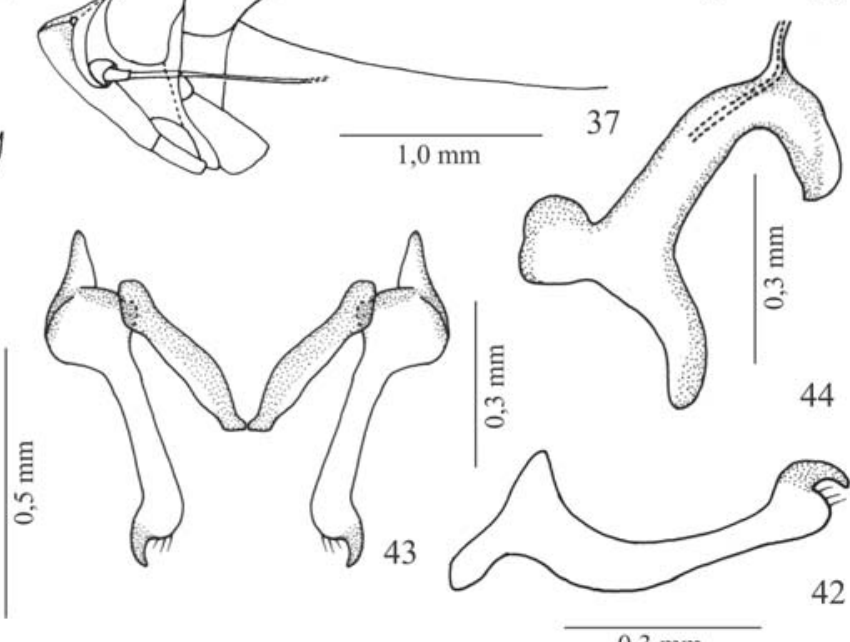

Figs. 35-45. Paracoelidiana morretensis sp. nov., holótipo macho: 35, cabeça, pronoto e escutelo, vista dorsal; 36, cabeça, vista frontal; 37, cabeça, pronoto e escutelo, vista lateral; 38, asa anterior; 39, pigóforo, vista lateral; 40, placas subgenitais, vista ventral; 41, placas subgenitais, vista lateral; 42, estilo, vista lateral; 43, estilos e conetivo, vista dorsal; 44, edeago, vista lateral; 45, edeago, vista dorsal.

\section{Paracoelidiana longipenis sp. nov.}

Figs. 24-34 e 59

\section{Localidade-tipo: Manaus, Amazonas, Brasil.}

Diagnose. Genitália masculina: pigóforo, em vista lateral, retangular, com dente ventral apical (Fig. 27); placas subgenitais com ápices arredondados e sem esclerotinização (Fig. 28); estilos longos e afilados (Figs. 29-30); edeago com aspecto alongado, ápice da haste voltado posteriormente e com processo pré-apical longo, curvado ventralmente, com margens serrilhadas (Figs. 31-32).

Medidas. Holótipo macho: comprimento total 5,75; comprimento mediano da coroa 0,55 ; distância transocular 1,20 ; distância interocular 0,65 ; comprimento mediano do pronoto 0,50 ; distância trans-humeral 1,35; comprimento mediano do escutelo 0,85 ; largura máxima do escutelo 0,90 ; comprimento da asa anterior 4,62; largura máxima da asa anterior 1,10; largura basal da fronte 0,50 ; comprimento da fronte 0,80 .

Descrição. Caracteres estruturais como na descrição genérica. Comprimento mediano da coroa aproximadamente igual à distância interocular e metade da distância transocular; fronte com comprimento cerca de 1,5 vezes sua largura basal; distância trans-humeral quase igual à distância transocular; asa anterior com comprimento aproximadamente quatro vezes sua largura máxima. Genitália masculina: pigóforo, em vista lateral, retangular, não estreitado apicalmente, com dente ventral apical; microcerdas na margem posterior, próximas ao dente apical (Fig. 27). Placas subgenitais triangulares, alargadas basalmente estreitando-se levemente no terço apical; quase inteiramente fusionadas entre si, exceto no quarto apical; ápices arredondados; não esclerosadas e com microcerdas no terço apical; cada placa com comprimento cerca de 3,5 vezes sua largura máxima (Fig. 28); em vista lateral, ápice retilíneo. Estilos simples, longos e afilados, com cerdas na porção pré-apical; margens lisas (Figs. 29-30). Conetivo com porção central alargada, cerca de metade do comprimento dos estilos e articulado à base do edeago (Fig. 30). Edeago, em vista lateral, estreito e afilado, com aspecto alongado; base com prolongamento ventral curto e apódema dorsal longo e espatulado; haste com ápice voltado posteriormente, não curvado dorsalmente; porção pré-apical sem lamelas e com processo longo, pontiagudo e de margens serrilhadas (Figs. 31-32); em vista dorsal, ápice com par de membranas laterais (Fig. 33); gonóporo apical. Tubo anal, em vista lateral, expandido no ápice, e ventralmente com ligação mediana dos lobos laterais (Fig. 34).

Fêmea. Desconhecida.

Coloração geral. Amarela com manchas laranjas; cabeça, em vista frontal, amarelo-escura, com pequenas manchas 


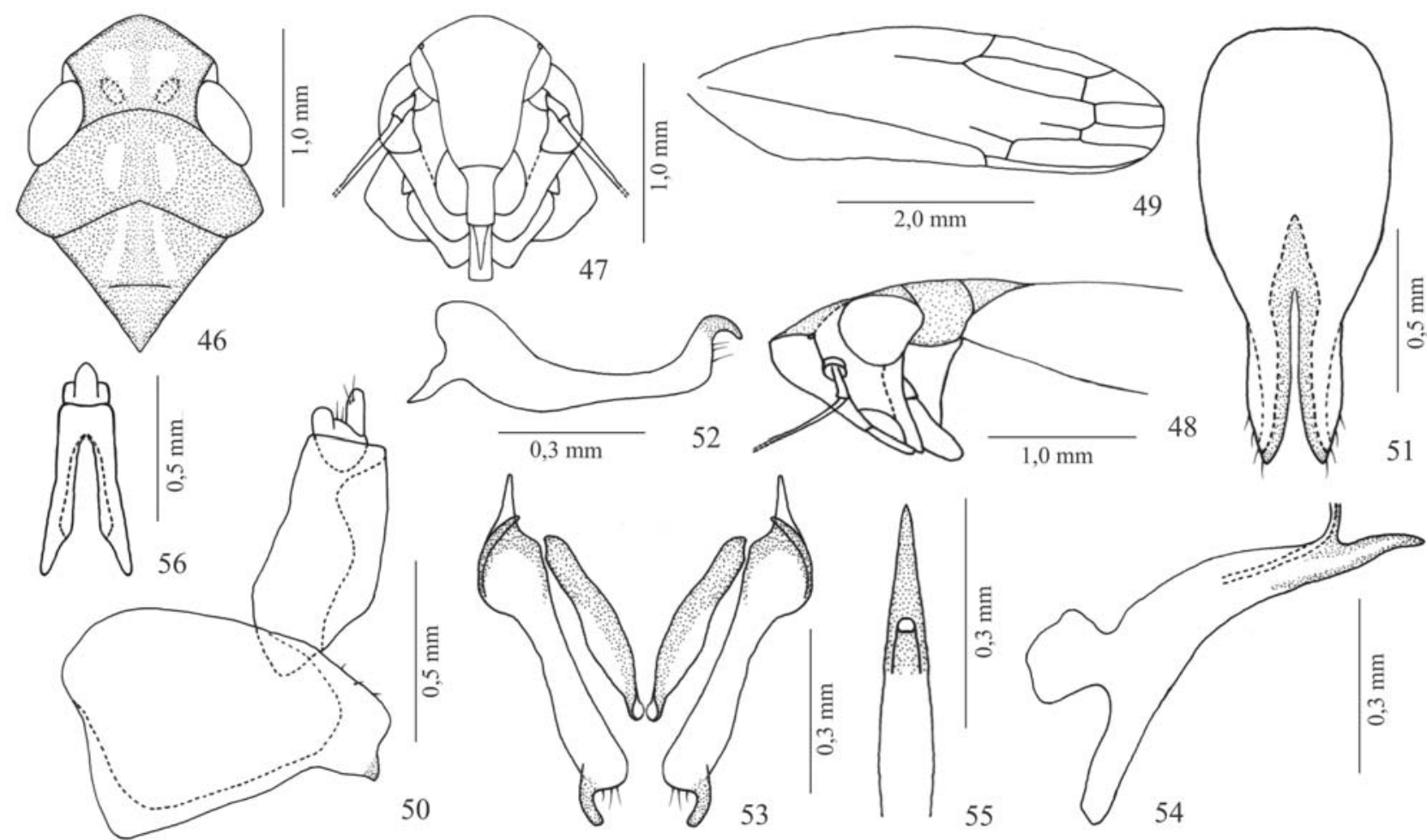

Figs. 46-56. Paracoelidiana recifensis sp. nov., holótipo macho: 46, cabeça, pronoto e escutelo, vista dorsal; 47, cabeça, vista frontal; 48, cabeça, pronoto e escutelo, vista lateral; 49, asa anterior; 50, pigóforo e tubo anal, vista lateral; 51, placas subgenitais, vista ventral; 52, estilo, vista lateral; 53, estilos e conetivo, vista dorsal; 54, edeago, vista lateral; 55, ápice do edeago, vista dorsal; 56, tubo anal, vista ventral.

laranjas ao redor dos ocelos (Fig. 25). Coroa quase que inteiramente laranja, com três faixas laranjas longitudinais, uma central estreita e duas laterais mais largas, e uma faixa transversal na margem anterior da mesma cor, unida às faixas longitudinais; duas manchas centrais amarelo-claras, estendendo-se e estreitando-se em direção à base da coroa. Pronoto amarelo-escuro, com um par de manchas centrais amarelo-claras e um par de manchas laterais da mesma cor, próximas aos ângulos laterais. Escutelo com duas manchas laterais amarelo-escuras e uma faixa central estreita da mesma cor, alargada no ápice (Fig. 24). Asas anteriores hialinas e amarelas, com veias da mesma cor; o clavo, margem anal e células apicais mais escurecidos, em tons amarelo-escuros a laranja. Asa posterior amarelada. Pernas amarelas com cerdas da mesma cor.

\section{Distribuição geográfica (Fig. 62). Brasil (Amazonas).}

Material examinado. Holótipo macho (INPA): BRASIL: Amazonas, Manaus, ZF2, Km 14, Torre, $02^{\circ} 35^{\prime} 21^{\prime \prime S}, 60^{\circ} 06^{\prime} 55^{\prime \prime W}$, 18-21.v.2004, lençol com luz mista e BLB, 40m de altura/ J.A. Rafael, F.B. Bacaro, F.F.Xavier Filho e A. Silva Filho leg.

Condição do holótipo. Lateral direita do tórax colada diretamente em alfinete entomológico, com cola branca comum; flagelos antenais, pernas anteriores, perna média direita, tarso da perna média esquerda, tarsos das pernas posteriores e ápice da asa anterior esquerda quebrados; abdome dissecado.
Comentários. Assemelha-se a P. hastata sp. nov. pelo formato das placas subgenitais e conetivo (Figs. 28 e 30). Porém, difere bastante desta e das demais espécies por possuir pigóforo quase retangular, não estreitado apicalmente e com dente apical ventral (Fig. 27); placas subgenitais sem esclerotinização (Fig. 28); estilos longos e afilados (Fig. 30) e edeago com aspecto geral alongado e ápice da haste voltado posteriormente (Figs. 31-32).

Etimologia. Do latim, longi $=$ longo, penis $=$ edeago, referindo-se ao aspecto geral do edeago, maior que o das demais espécies, e com processo pré-apical longo e afilado.

\section{Paracoelidiana morretensis sp. nov.}

Figs. 35-45 e 60

\section{Localidade-tipo: Morretes, Paraná, Brasil.}

Diagnose. Genitália masculina: pigóforo, em vista lateral, estreitando-se em direção ao ápice, com dente ventral apical (Fig. 39); placas subgenitais fortemente esclerosadas medianamente e nos ápices, estes afilados, pontiagudos e curtos, levemente curvados para cima e para fora (Figs. 4041); porção pré-apical do edeago com processo arredondado curvado ventralmente e com dentículo no ápice (Fig. 44).

Medidas. Holótipo macho: comprimento total 5,64; comprimento mediano da coroa 0,60 ; distância transocular 1,25; 
distância interocular 0,70 ; comprimento mediano do pronoto 0,50; distância trans-humeral 1,40; comprimento mediano do escutelo 0,85 ; largura máxima do escutelo 0,90 ; comprimento da asa anterior 4,56; largura máxima da asa anterior 1,24; largura basal da fronte 0,50 ; comprimento da fronte 0,90 .

Descrição. Caracteres estruturais como na descrição genérica. Comprimento mediano da coroa aproximadamente igual à distância interocular e metade da distância transocular; fronte com comprimento cerca de duas vezes sua largura basal; distância trans-humeral quase igual à distância transocular; asa anterior com comprimento cerca de 3,5 vezes sua largura máxima. Genitália masculina: pigóforo, em vista lateral, triangular, alargado nos terços basal e médio, estreitando-se em direção ao terço apical; ápice arredondado com dente ventral esclerosado; microcerdas no ápice (Fig. 39). Placas subgenitais triangulares, alargadas basalmente estreitandose em direção ao ápice; fusionadas entre si em toda metade basal; ápices afilados, pontiagudos e curtos, levemente curvados para cima e para fora; fortemente esclerosadas medianamente e nos ápices; cada placa com comprimento 3,5 vezes sua largura máxima; microcerdas nas margens externas da metade apical (Fig. 40); em vista lateral, ápice curto e curvado para cima (Fig. 41). Estilos simples, longos e engrossados, com cerdas na porção pré-apical e margens lisas (Figs. 42-43). Conetivo cerca de metade do comprimento dos estilos, articulado à base do edeago (Fig. 43). Edeago, em vista lateral, mais alargado e mebranoso nos terços basal e médio, fortemente estreitado no terço apical; base com prolongamento ventral engrossado e apódema dorsal curto, aproximadamente arredondado; haste com terço médio curvado posteriormente e ápice curvado dorsalmente; porção pré-apical sem lamelas e com processo arredondado curvado ventralmente, com dentículo no ápice (Fig. 44); em vista dorsal, processo préapical com aspecto cilíndrico (Fig. 45); gonóporo apical. Tubo anal quebrado no holótipo.

\section{Fêmea. Desconhecida.}

Coloração geral. Amarela com manchas laranjas; fronte com manchas pequenas, laranjas, próximas aos ocelos (Fig. 36); coloração da cabeça, pronoto e escutelo semelhante à de $P$. lamellata sp. nov., mas com os ângulos laterais do escutelo inteiramente laranjas (Fig. 35). Asas anteriores quebradas. Asa posterior hialina, com veias amarelas a laranjas. Pernas amarelas com cerdas da mesma cor, pernas posteriores com manchas laranjas nas tíbias e tarsos.

Distribuição geográfica (Fig. 62). Brasil (Paraná).

Material examinado. Holótipo macho (DZUP): BRASIL: Paraná, Morretes, 19-20.xi.1984, (IAPAR), C.I.I.F (Luminosa)/ Dep[artamen]to [de] Zool[ogia da] U[niversidade] F[ederal do] Paraná/ DZUP \# 082922.

Condição do holótipo. Flagelos antenais, pernas anteriores e asas anteriores quebradas; lateral direita do tórax colada
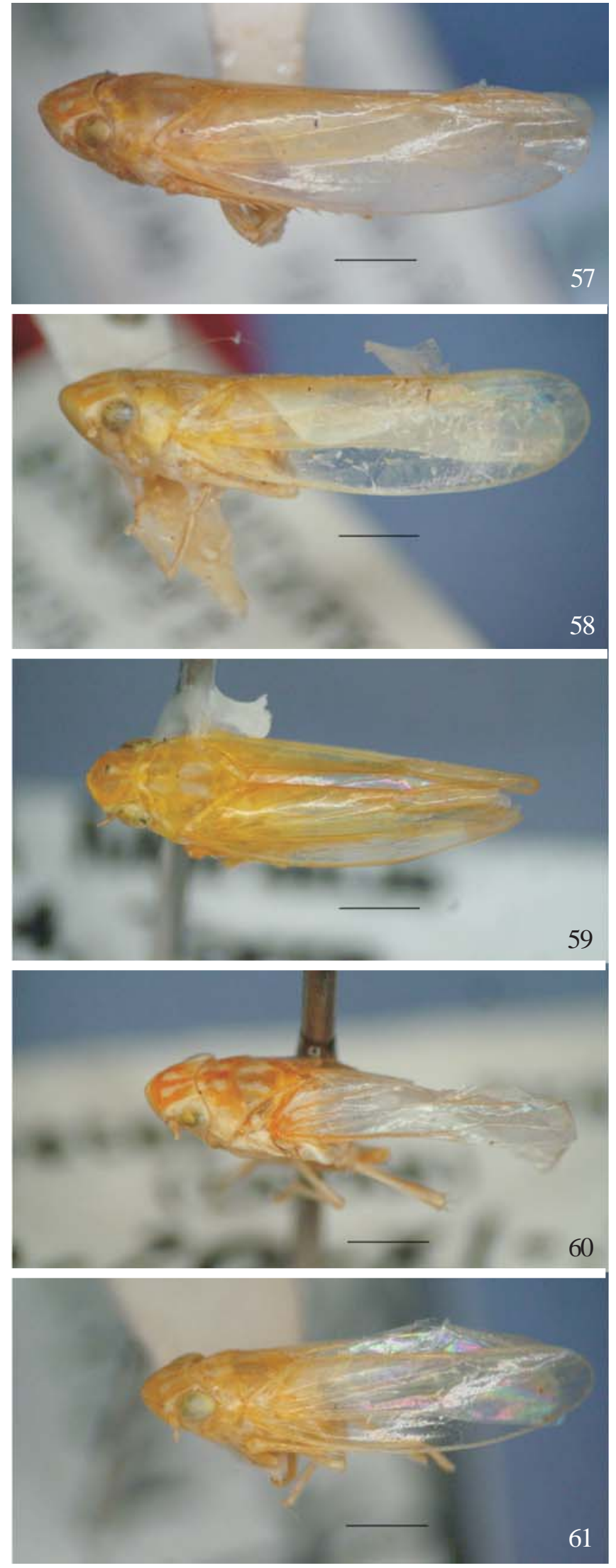

Figs. 57-61. Holótipos machos: 57, Paracoelidiana hastata sp. nov.; 58, Paracoelidiana lamellata sp. nov.; 59, Paracoelidiana longipenis sp. nov.; 60, Paracoelidiana morretensis sp. nov.; 61, Paracoelidiana recifensis $\mathbf{s p . ~ n o v . ~ E s c a l a s ~}=1,0 \mathrm{~mm}$. 


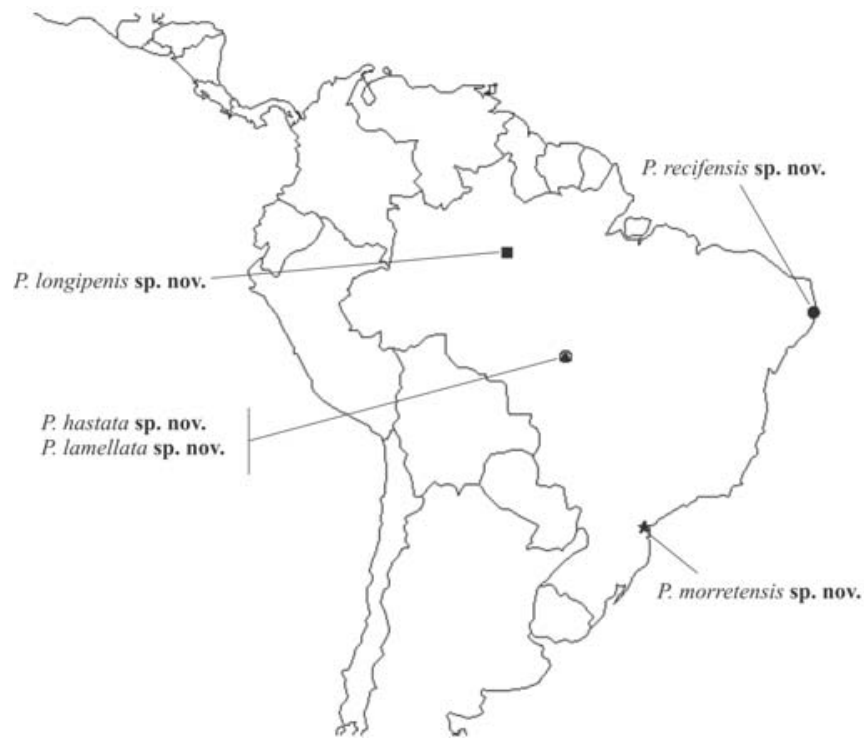

Fig. 62. Mapa de distribuição das espécies de Paracoelidiana gen. nov.

diretamente em alfinete entomológico, com cola branca comum; abdome dissecado. Observação: as asas anteriores do holótipo estão quebradas e perdidas, mas o espécime e suas asas haviam sido previamente medidos e ilustrados por Larissa B. Chiamolera, estando suas anotações arquivadas no Laboratório de Bionomia e Sistemática de Cicadellidae da Universidade Federal do Paraná.

Comentários. Assemelha-se a P. lamellata sp. nov. pelo formato das placas subgenitais e edeago (Figs. 40 e 44). Difere desta espécie por possuir na porção pré-apical do edeago processo arredondado curvado ventralmente, com dentículo no ápice (Figs. 44-45). Distingue-se das demais espécies do gênero principalmente pela morfologia do pigóforo (Fig. 39).

Etimologia. O nome da espécie refere-se à localidade-tipo, a cidade de Morretes, no Estado do Paraná, Brasil.

\section{Paracoelidiana recifensis $\mathbf{S p .}$ nov.} Figs. 46-56 e 61

\section{Localidade-tipo: Recife, Pernambuco, Brasil.}

Diagnose. Genitália masculina: pigóforo, em vista lateral, estreitando-se em direção ao ápice e com dente ventral apical esclerosado (Fig. 50); placas subgenitais fortemente esclerosadas medianamente e nos ápices, estes estreitados, angulados e retos (Fig. 51); porção pré-apical do edeago com processo estreitado apicalmente, com ápice agudo e reto (Figs. 54-55).

Medidas. Holótipo macho: comprimento total 5,87; comprimento mediano da coroa 0,50 ; distância transocular 1,20; distância interocular 0,65 ; comprimento mediano do pronoto
0,50; distância trans-humeral 1,30; comprimento mediano do escutelo 0,85 ; largura máxima do escutelo 0,80; comprimento da asa anterior 4,60; largura máxima da asa anterior 1,25; largura basal da fronte 0,50 ; comprimento da fronte 0,75 .

Descrição. Caracteres estruturais como na descrição genérica. Comprimento mediano da coroa aproximadamente igual à distância interocular e metade da distância transocular; fronte com comprimento cerca de 1,5 vezes sua largura basal; distância trans-humeral quase igual à distância transocular; asa anterior com comprimento aproximadamente quatro vezes sua largura máxima. Genitália masculina: pigóforo, em vista lateral, triangular, alargado nos terços basal e médio, estreitando-se em direção ao ápice; terço apical com dente ventral esclerosado e microcerdas (Fig. 50). Placas subgenitais triangulares, alargadas basalmente estreitando-se em direção ao ápice; fusionadas entre si até o terço apical; ápices estreitados e angulados, retos; fortemente esclerosadas medianamente e nos ápices; cada placa com comprimento cerca de 4,5 vezes sua largura máxima; microcerdas nas margens externas da metade apical (Fig. 51); em vista lateral, ápice retilíneo. Estilos simples, longos e engrossados, com cerdas na porção pré-apical e margens lisas (Figs. 52-53). Conetivo cerca de metade do comprimento dos estilos, articulado à base do edeago (Fig. 53). Edeago, em vista lateral, mais alargado e membranoso nos terços basal e médio, fortemente estreitado no terço apical; base com prolongamento ventral engrossado e apódema dorsal curto, aproximadamente arredondado; haste com terço médio curvado posteriormente e ápice curvado dorsalmente; porção pré-apical sem lamelas e com processo estreitado apicalmente, com ápice agudo e reto (Fig. 54); em vista dorsal, processo pré-apical com aspecto triangular (Fig. 55); gonóporo apical. Tubo anal, em vista ventral, com dobra interna medianamente (Fig. 56).

Fêmea. Desconhecida.

Coloração geral. Amarela a laranja; cabeça, em vista frontal, sem manchas (Fig. 47). Coroa inteiramente laranja com duas manchas centrais amarelas. Pronoto quase inteiramente laranjaclaro com duas manchas centrais amarelas. Escutelo laranjaclaro com duas faixas longitudinais laterais amareladas; segue o padrão de coloração das demais espécies, porém, as faixas da cabeça, pronoto e escutelo, não são bem definidas, e a coloração laranja-clara predomina dorsalmente (Fig. 46). Asas anteriores e posteriores amarelas com veias da mesma cor. Pernas amarelas com cerdas da mesma cor.

Distribuição geográfica (Fig. 62). Brasil (Pernambuco).

Material examinado. Holótipo macho (DZUP): BRASIL: Pe[rnambuco], Recife, vi.1996, J. Ferreira leg./ DZUP \# 082923.

Condição do holótipo. Tórax e pernas colados ventralmente em triângulo entomológico; flagelos antenais quebrados; perna média direita e pernas posteriores com tarsos quebrados; abdome dissecado. 
Comentários. Assemelha-se a P. morretensis sp. nov. em relação ao formato do pigóforo (Fig. 50) e a P. lamellata sp. nov. pela presença de esclerotinização na porção mediana das placas subgenitais (Fig. 51). Entretanto difere dessas espécies e das demais, pelo formato das placas subgenitais, cujo ápice é reto (Fig. 51), e pelo formato do processo pré-apical do edeago, estreitado, curto, agudo e retilíneo (Figs. 54-55).

Etimologia. O nome da espécie refere-se à localidade-tipo, a cidade de Recife, no Estado do Pernambuco, Brasil.

Agradecimentos. Aos Drs. José Albertino Rafael e Augusto L. Henriques (INPA) pelo empréstimo dos espécimes, Dras. Lúcia Massutti de Almeida e Cibele Stramare Ribeiro-Costa por gentilmente permitirem o uso do equipamento fotográfico presente em seu laboratório, à Larissa de Bortolli Chiamolera por fornecer suas anotações sobre Neocoelidiinae e ao Conselho Nacional de Desenvolvimento Científico e Tecnológico (CNPq) pela bolsa de doutorado concedida à primeira autora e pela bolsa de produtividade concedida ao segundo autor.

\section{REFERÊNCIAS}

Comstock, J. H. \& J. G. Needham. 1898. The wings of insects. American Naturalist 32: 43-48, 81-89, 231-257, 335-340, 413-424, 561-565, 768-777, 903-911.

Comstock, J. H. \& J. G. Needham. 1899. The wings of insects. American Naturalist 33: 117-126, 573-582, 845-860.

Dietrich, C. H. 2003. Someunusual neotropical Neocoelidiinae with a redefinition of the subfamily (Hemiptera: Membracoidea: Cicadellidae). Annals of the Entomological Society of America 96: 700-715.

Dietrich, C. H. 2004. Phylogeny of the leafhopper subfamily Evacanthinae with a review of neotropical species and notes on related groups (Hemiptera: Membracoidea: Cicadellidae). Systematic Entomology 29: 455-487.
Hamilton, K. G. A. 1981. Morphology and evolution of the rhynchotan head (Insecta: Hemiptera, Homoptera). Canadian Entomologist 113: 953-974.

Kramer, J. P. 1964. A generic revision of the leafhopper subfamily Neocoelidiinae (Homoptera: Cicadellidae). Proceedings of the United States National Museum 115: 259-287.

Marques-Costa, A. P. \& R. R. Cavichioli. 2007a. Descrição de um novo gênero amazônico de Neocoelidiinae (Hemiptera, Auchenorrhyncha, Cicadellidae). Revista Brasileira de Zoologia 24: 228-232.

Marques-Costa, A. P. \& R. R. Cavichioli. 2007b. Neocoelindroma, gênero novo de Neocoelidiinae (Hemiptera, Auchenorrhyncha, Cicadellidae) da Região Neotropical. Revista Brasileira de Zoologia 24: 233-237.

Mejdalani, G. 1998. Morfologia externa dos Cicadellinae (Homoptera, Cicadellidae): comparação entre Versigonalia ruficauda (Walker) (Cicadellini) e Tretogonia cribrata Melichar (Proconiini), com notas sobre outras espécies e análise da terminologia. Revista Brasileira de Zoologia 15: 451-544.

Nielson, M. W. \& W. J. Knight. 2000. Distributional patterns and possible origin of leafhoppers. (Homoptera, Cicadellidae). Revista Brasileira de Zoologia 17: 81-156.

Oman, P. W. 1949. The Nearctic leafhoppers (Homoptera: Cicadellidae). A generic classification and check list. Memoirs of the Entomological Society of Washington 3: 1-253.

Rakitov, R. A. 1998. On differentiation of cicadellid leg chaetotaxy. Russian Entomological Journal 6: 7-27.

Triplehorn, C. A. \& N. F. Johnson. 2005. Borror and DeLong's Introduction to the Study of Insects. Belmont, Thomson Brooks/ Cole, 7th Edition, 864p.

Young, D. A. 1968. Taxonomic study of the Cicadellinae (Homoptera, Cicadellidae). Part 1. Proconiini. Bulletin of the United States National Museum 261: 1-287.

Young, D. A. 1977. Taxonomic study of the Cicadellinae (Homoptera: Cicadellidae). Part 2. New World Cicadellini and the genus Cicadella. Bulletin of the North Carolina Agricultural Experiment Station 239: VI+1135p.

Young, D. A. 1986. Taxonomic study of the Cicadellinae (Homoptera: Cicadellidae). Part 3. Old World Cicadellini. Bulletin of the North Carolina Agricultural Experiment Station 281: 1-639.

Recebido em 17/11/2006; aceito em 29/03/2007 